\section{Is psychosurgery safer than section 57?}

DeAr SIRS

Section 57, Mental Health Act 1983, is mainly concerned with the regulation of psychosurgery in England and Wales. Many consider it unfortunate that the Section was amended on the basis of a proposal by a single Member of Parliament, Mr Terry Davis, which was that this section should apply to every patient being considered for psychosurgery, whether subject to compulsory detention or not (Rawnsley, 1982). This was presumably because anyone who consents to psychosurgery needs their head examined anyway. Thus, patients who are entirely free individuals must, regardless, compulsorily attend an interview with a doctor and two others appointed by the Mental Health Act Commission. Whatever the decision of the Commissioners, they will only see the patient once and yet their decision is final. There is no appeal except to the High Court (Dyer, 1988).

There have now been two deaths associated with Section 57; the first was due to suicide after commissioners had refused to agree to our offer to accept the patient for psychosurgery (Bridges, 1984a, $1984 b$ ). The subsequent comments of the then Chairman of the MHA Commission seemed to be less than sympathetic (Colville, 1985).

The second and recent death involved Mrs G., who was 68 years old. This lady was referred to us for psychosurgery. She had been in virtually continuous depressive stupor for over a year and no treatments were effective. It was clear to us that she was suitable for a stereotactic subcaudate tractotomy (SST) and this information was duly passed to the Commission. We pointed out to them the problems with communication and we explained that occasionally, for a few days at a time, Mrs G. improved to the extent that she was capable of some conversation. We suggested that the Commission might like to send a doctor during one of these periods but the Commission stated its policy that Mrs G. needed to be seen by three Commissioners when she could express her formal consent and with an operation date available. This was impossible to arrange in the clinical circumstances.

Therefore, the patient was admitted to this Unit in order to try high-dose antidepressant medication in the hope that this would produce sufficient improvement for her to express her consent or otherwise. However, medication of various kinds could not be given in sufficiently high doses because of intolerable side-effects and so this attempt at treatment was not successful. Later, as the clinical situation was not improving, the referring psychiatrist asked our further advice and we again contacted the Commission. This time a meeting was arranged between myself and representatives of the Section 57 Panel. There was a useful exchange of views and a flexible plan was agreed. A doctor would be appointed who would be available to visit Mrs G. at short notice during one of her lucid periods.

Meanwhile, further legal advice was to be obtained as how best to manage this sort of problem when the patient is too ill to consent to have the only treatment that is likely to help. Sadly, just as arrangements were being made which appeared to offer hope for Mrs G., she died with a chest infection. Of course, one cannot avoid feeling that the long period of stupor had significantly contributed to the final outcome.

Before the advent of Section 57, this Unit had to establish its own ethical practices. We naturally accepted that the avoidance of fatal outcomes to refractory psychiatric illnesses was an over-riding concern. Hence, if we were sure that a patient had expressed unequivocal agreement at some time when capable of this, and if the nearest relative was entirely in favour of surgery, then we would operate without expressed consent at that time. Indeed, depressive stupor does particularly well with SST. In the case of Mrs G., her husband pleaded for more effective treatment and he kept asking us to carry out psychosurgery, which we were forced by law to deny him. He could not understand how a legal committee was able to stop attempts to treat his wife without anyone from the committee even seeing her or obtaining his views.

This sad case suggests that the medical ethic of the imperative need to preserve life seems to have given way to what might be called the anti-psychiatry ethic. Human rights must not be violated even if the cost is death. Is this what Parliament intended? If so, then a wide public debate is required to review this major moral change. If Parliament did not intend this then Section 57 must be reconsidered.

Since it was set up the Commission has been involved with about 125 patients being considered for psychosurgery and at least two have died as a result. The use of Section 57 is thus associated with a death rate of $1.6 \%$. During about 25 years we have now carried out over 1200 operations and there has been one surgical death, a rate of $0.08 \%$ and 20 times lower.

PAUL BRIDGes

Geoffrey Knight National Unit for Affective Disorders Brook General Hospital

London SE18 4LW

\section{References}

Bridges, P. K. (1984a) Psychosurgery and the Mental Health Act Commission. Psychiatric Bulletin, 8, 146-148. (1984b) Addendum to Psychosurgery and the Mental Health Act Commission. Psychiatric Bulletin, 8, 172.

Colville, Lord (1985) The Mental Health Act Commission and Second Opinions. Psychiatric Bulletin, 9, 2-3.

DYER, C. (1988) Mental Health Commission defeated over paedophile. British Medical Journal, 296, 1660.

RAWNsLeY, K. (1982) The Mental Health (Amendment) Act. Psychiatric Bulletin, 6, 227. 